\title{
Algorithm Development for Satellite Synthetic Aperture Radar (SAR) Classification and Mapping of Great Lakes Ice Cover
}

\author{
$\begin{array}{lll}\text { G. A. LESHKEVICH } & \text { S. V. NGHIEM } & \text { R. } \\ & \text { KWOK }\end{array}$ \\ 'Great Lakes Environmental Research Laboratory \\ National Oceanic and Atmospheric Administration \\ 2205 Commonwealth Blvd., Ann Arbor, Michigan 48105, U.S.A. \\ Tel: 734-741-2265, Fax: 734-741-2055, E-mail:leshkevich@glerl.noaa.gov \\ ${ }^{2}$ Jet Propulsion Laboratory, California Institute of Technology, MS 300-235 \\ 4800 Oak Grove Drive, Pasadena, California 91109, U.S.A. \\ Tel: 818-354-2982, Fax: 818-393-3077, E-mail: nghiem@solar.jpl.nasa.gov
}

\begin{abstract}
Computer analysis of ERS-1 and RADARSAT ScanSAR narrow images of Great Lakes ice cover using a supervised (level slicing) classification technique indicates that different ice types in the ice cover can be identified and mapped and that wind speed and direction can have a strong influence on the backscatter from open water. During the 1997 winter season, shipborne polarimetric backscatter data using the Jet Propulsion Laboratory (JPL) C-band scatterometer, together with surface-based ice physical characterization measurements and environmental parameters were acquired concurrently with RADARSAT and ERS-2 overpass. This data set was processed to radar cross-section and will establish a library of signatures (look-up table) for different ice types to be used in the machine classification of calibrated satellite SAR data.
\end{abstract}

\section{INTRODUCTION}

Owing to the size and extent of the Great Lakes and the variety of ice types and features found there, the timely and objective qualities inherent in computer processing of satellite data make it well suited for such a purpose. However, during winter months cloud cover over the Great Lakes impairs the use of satellite imagery from passive sensors operating in the visible, near infrared, and thermal infrared regions, and passive microwave data lacks the spatial resolution required for monitoring and analysis of Great Lakes ice cover. The all-weather, day/night viewing capability of satellite Synthetic Aperture Radar (SAR) makes it a unique and valuable tool for Great Lakes ice identification and mapping provided that data analysis techniques can be developed. The European Remote-Sensing Satellite (ERS-1) launched in 1991 with a vertically polarized SAR and more recently, RADARSAT, an operational satellite carrying a SAR operating at $5.3 \mathrm{GHz}$ (C-Band) with a horizontal polarization launched in 1995 , provide an opportunity for this development.

U.S. Government work not protected by U.S. copyright
Results of an earlier study using ERS-1 SAR data concluded that SAR is a unique and valuable tool for Great Lakes ice identification and mapping [1]. To assess the utility of RADARSAT SAR data for Great Lakes ice analysis, a data set for Lake Superior was established covering the period from 13 to 21 March 1996. This data set includes RADARSAT ScanSAR data, AVHRR imagery, U.S. Coast Guard Side Looking Airborne Radar (SLAR), and ground (in situ) data consisting of ice charts, photographs, and video taken from the USCGC Mackinaw, a Coast Guard ice breaker, and from a Coast Guard helicopter. Meteorological data from selected ground stations are also included. Color photographs and video along with ice charts and GPS data were obtained along the ship track and over the study areas from altitudes ranging from approximately 200 to $400 \mathrm{~m}$. Ice thickness was obtained by measurement and visual examination en route. RADARSAT data from the Gatineau readout station in Canada were received at the National Ice Center (NIC) in Suitland, Maryland via a link between the U.S. and Canadian Ice Centers and forwarded to the Great Lakes Environmental Research Laboratory. Two ScanSAR Wide images (13 and 20 March) having a nominal $100 \mathrm{~m}$ resolution and a ScanSAR Narrow image (16 March) of western Lake Superior having a nominal $50 \mathrm{~m}$ resolution [2] were used in this analysis.

Ice types and conditions varied over the lake during the study period. Measured and observed ice thickness ranged from $38 \mathrm{~cm}$ of "lake ice" in Lake Munuscong to approximately $1-2 \mathrm{~cm}$ of "new ice" in the western portion of the lake. Ice types encountered included "lake (black) ice", "lake ice" covered with "snow ice", "pancake ice", "new ice", and a thick $(\sim 2-3 \mathrm{~m})$ consolidated "brash ice"[3].

\section{METHODS}

The SAR images were clisplayed and analyzed using commercial and government-developed image processing software. Photographs were used along with ice charts and field notes to interpret and analyze ice types and patterns seen 
in the SAR images. It should be noted that the precommissioned scenes received from the Gatineau readout station and used in this study were "banded" or "striped" evidently due to an artifact in processing. Although training sets were taken and processed within a "band", they could not be used to classify the entire scene (eg. results of the classification outside the band in which the training set was taken could be subject to error). Calibration should solve this problem.

A supervised, level slicing classification [4], based on a comparison of brightness or digital values in the SAR scene representing known ice types as identified in the ground data, was used in this initial analysis. Using photographs, ice charts, and field notes, two ice types (snow ice and new ice) and open water were identified in the computer displayed SAR image (16 March), and a representative training set, consisting of a range of digital values, was extracted for each type. A color was assigned to each type (range of values) and then applied to the entire scene producing a color-coded classified image. However, as explained above, the classification is only valid for the "band" in which the training set was taken.

\section{RESULTS AND DISCUSSION}

Analysis of the image indicates that open water and different ice types in the ice cover can be identified, classified, and mapped in RADARSAT imagery. In addition, wind has a strong influence on the backscatter from open water as observed in the other RADARSAT images [5]. Since RADARSAT data are of single frequency and single polarization, the overlap in backscatter ranges among different ice types and open water (depending on wind speed and direction) can cause some difficulties in lake ice remote sensing.

\section{WINTER EXPERIMENTS - 1997}

To continue the development and validation of an algorithm for remote sensing of Great Lakes ice using SAR data, we conducted two winter experiments across the Straits of Mackinac and Lake Superior during the 1997 winter season. The experiments acquired shipborne polarimetric backscatter data together with surface-based ice physical characterization measurements and environmental parameters in conjunction with aerial ice reconnaissance. The experiment was timed to include RADARSAT and ERS-2 SAR imaging .

In these experiments, the Jet Propulsion Laboratory polarimetric scatterometer was mounted onboard the U.S. Coast Guard ice breakers Biscayne Bay and Mackinaw. The scatterometer operates at $\mathrm{C}$ band and has full polarimetric capability [6], including horizontal (HH) and vertical (VV) co-polarizations so that the results are applicable to
RADARSAT SAR, ERS SAR, and the future ENVISAT SAR data. A video camera was set up to observe lake ice types and surface conditions in the same direction of the scatterometer incidence at the same time and location. An example of backscatter signatures (in the time domain) from lake ice with a top layer of frozen slush having a rippled texture is presented in Fig. 1. Since different (major) ice types have characteristic radar backscatter at given polarization, incidence angle, and temperature, a look-up table of measured backscatter can be used to classify and map different ice types in calibrated satellite SAR imagery.

\section{ACKNOWLEDGMENTS}

SAR data for this study were provided by the Canadian Space Agency. The authors gratefully acknowledge individuals at the Ice Center Environment Canada and the National Ice Center for their efforts in obtaining and making available the RADARSAT SAR imagery. Our appreciation and thanks go to the U.S. Coast Guard, Ninth District for providing the ship, helicopter, and ground support essential to the success of these experiments and to the Houghton Memorial Airport. JPL contribution was performed by the CSMT, JPL, California Institute of Technology and was sponsored by NOAA through an agreement with NASA. GLERL Contribution No. 1094.

\section{REFERENCES}

[1] G.A. Leshkevich, W. Pichel, P. Clemente-Colon, R. Carey, and G. Hufford, "Analysis of coastal ice cover using ERS-1 SAR data," Int. J. Remote Sensing, vol. 16, no.17, pp. 3459-3479, 1995.

[2] RADARSAT International, RADARSAT Illuminated, RADARSAT International, Richmond, British Columbia, 1995, p.59.

[3] Ice Glossary, U.S. Department of Comerce, National Oceanic and Atmospheric Administration, National Ocean Survey, Lake Survey Center, Detroit, MI (HO 75-602) p.9, 1971.

[4] T.M. Lillesand and R.W. Kiefer. Remote Sensing and Image Interpretation, John Wiley and Sons, New York, 1979, p. 612.

[5] G.A. Leshkevich, S.V. Nghiem, S.V., and R. Kwok, "Satellite SAR Remote Sensing of Great Lakes Ice Cover Using RADARSAT Data," In Proceedings: Fourth International Conference on Remote Sensing for Marine and Coastal Environments, Orlando, FL, 17-19 March, ERIM, pp. I-126-134, 1997.

[6] S.V. Nghiem, R. Kwok, S. H. Yueh, A.J. Gow, D.K. Perovich, J.A. Kong, and C.C. Hsu, "Evolution in polarimetric signatures of thin saline ice under constant growth," Radio Science, vol. 32, no. 1, pp.127-151,1997. 

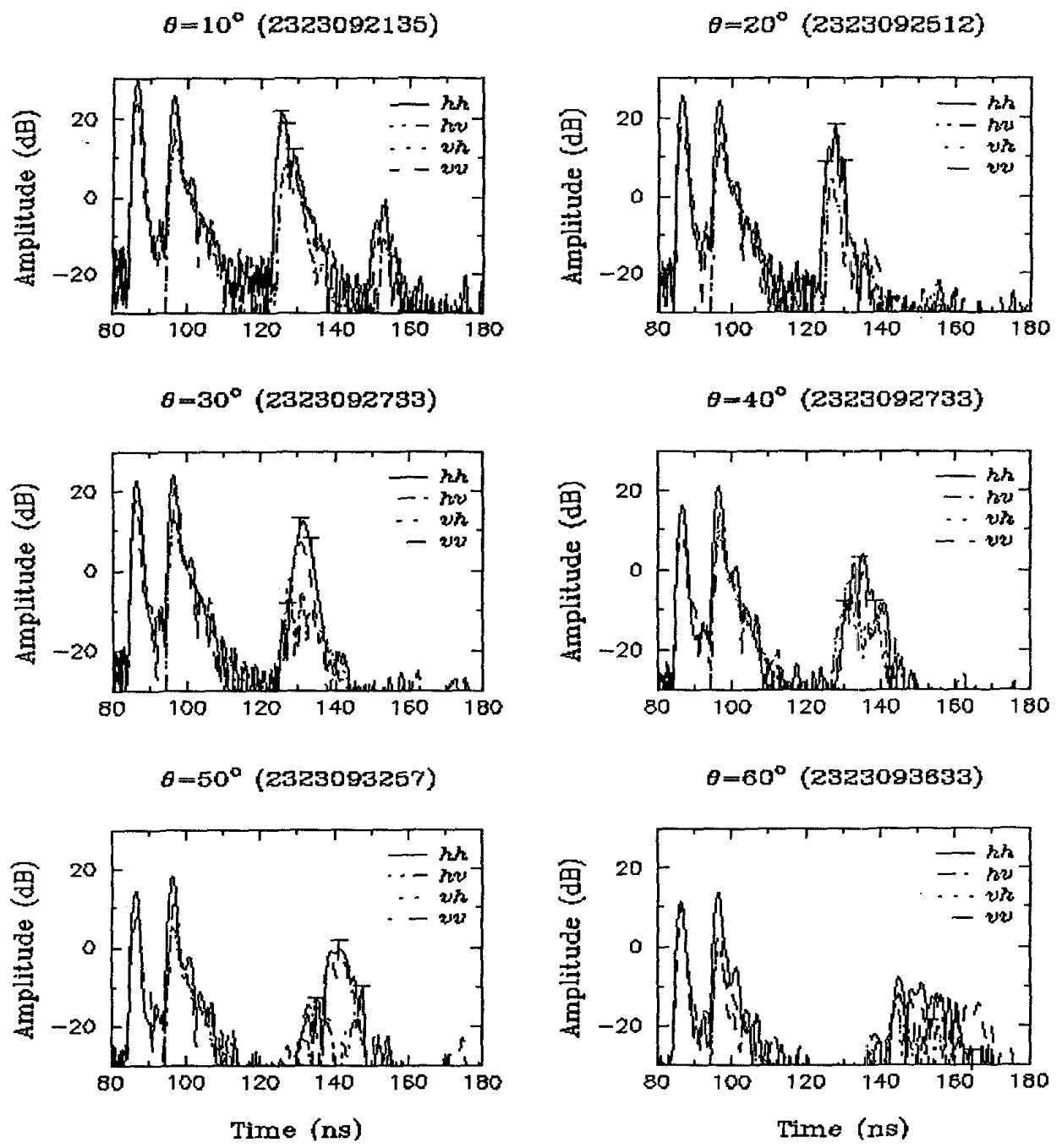

Figure 1. Backscatter signatures (time domain) from lake ice with a top layer of frozen slush having a rippled texture. 